\title{
Preceptor support to improve nurse competency and satisfaction: A pilot study of novice nurses and preceptors in a pediatric intensive care unit
}

\author{
Kirsten A. Hickerson ${ }^{* 1,2}$, Mary F. Terhaar ${ }^{3}$, Laura A. Taylor ${ }^{4}$ \\ ${ }^{1}$ School of Nursing, University of Pennsylvania, Pennsylvania, United States \\ ${ }^{2}$ The Children's Hospital of Philadelphia, Pennsylvania, United States \\ ${ }^{3}$ Case Western Reserve University, Cleveland, Ohio, United States \\ ${ }^{4}$ Daniel K. Inouye Graduate School of Nursing Uniformed Services University, Bethesda, Maryland, United States
}

Received: May 13, 2016

DOI: $10.5430 /$ jnep.v6n12p57
Accepted: July 18, 2016

Online Published: July 24, 2016

\begin{abstract}
Objective: To develop and implement an evidence-based preceptor program that improves satisfaction and competency among pediatric intensive care nurses. The preparation-practice gap-defined as the discrepancy between new graduates' abilities and the demands of their first jobs-increases stress, turnover, costs and medical errors. Preceptor programs and strong preceptor teaching might be able to narrow this gap.

Methods: We developed, implemented and evaluated a Preceptor Support Program to bridge the preparation-practice gap: The Preceptor Support Program. This program integrated electronic progress monitoring and communication; preceptor huddles; checklists; online resources and hands-on teaching materials. Improvements in competency and satisfaction were measured, using pre/post testing for 34 preceptors. For 30 novice nurses, satisfaction ratings were obtained and competency was measured with pre/post administration of the Basic Knowledge Assessment Test (BKAT).

Results: Novice nurse BKAT scores (competency measurement) increased from 73 to $83(p<.001)$. Novice nurse satisfaction increased from 3.1 to 3.6. Preceptor satisfaction increased from 3.0 to $3.2(p=.04)$ and preceptor competence was increased from 4.7 to 4.8 .

Conclusions: Our evidence-based Preceptor Support Program improved satisfaction and competency for both the preceptors and novice nurses in our Pediatric ICU.
\end{abstract}

Key Words: Novice nurse, Preceptor support, Preceptor teaching, Preparation-practice gap, Nurse competency, New graduate nurses, Pediatric intensive care unit

\section{INTRODUCTION}

Academic preparation in nursing school has traditionally focused on evidence-based care, scientific inquiry, patient engagement and problem-based pedagogy. Nursing faculty aim to meet these educational objectives, and groom the new graduate nurse for competence and success in the workplace.
Nevertheless, there is a significant chasm between new graduates' abilities when they finish school and the demands of their first jobs, commonly called "the preparation-practice gap".

The existence of a preparation-practice gap can be inferred from data reported by the Advisory Board: namely, that

\footnotetext{
* Correspondence: Kirsten A. Hickerson; Email: hickerso@nursing.upenn.edu; Address: School of Nursing, University of Pennsylvania, Pennsylvania, United States.
} 
although $90 \%$ of nursing faculty are satisfied with their students' progress, nearly all $(95 \%$ of 5,700$)$ nurse administrators felt that these recent graduates were not prepared for work and less-than-competent in 36 core nursing skills. ${ }^{[1]}$ Along those lines, other investigations have reported a mismatch between nurse managers' and preceptors' expectations and the novice nurses' abilities. ${ }^{[2-6]}$

The "practice-preparation gap" has been said to produce a number of adverse effects, including increased turnover, high stress levels among novice nurses, increased costs to the employer and patient safety events. ${ }^{[7-13]}$ This makes intuitive sense: inadequately prepared nurses are less likely to thrive; in turn, these nurses may leave their jobs prematurely (thereby increasing turnover) or they may stay, under stress and duress, and perform less than optimally. This leads to costs to the institution, both in terms of finding replacements for those who leave or to managing suboptimal patient outcomes and medical errors.

An integrative review of the literature regarding on-the-job remediation for novice nurses, suggests that the best options are nurse residency programs or preceptor programs. Residency programs have been shown to improve nurse satisfaction and decrease turnover yet these programs can be very expensive. ${ }^{[9,10,14,15]}$ The Preceptor Model is another appealing approach, combining some of the formal structures of residency, but tailored more to the specific needs of the novice nurse, in context of his or her job. Preceptorships have been shown decrease adverse events and turnover by minimizing stress, creating correct incentives, identifying the novice's deficiencies in a non-threatening manner and using helpful forms and tools consistently. ${ }^{[16-20]}$

Based on these findings, an initiative was undertaken at the Pediatric Intensive Care Unit (PICU) at The Children's Hospital of Philadelphia to improve preceptor performance. The intervention centered on information technology enhancement, use of checklists and frequent group meetings (preceptor huddles) for moral support and teaching. Outcomes were assessed in the realm of preceptor self-reported competence improvement, satisfaction among both preceptors and novice nurses and cognitive competence of novices as demonstrated on a written exam.

\subsection{Background}

The Preceptor Support program was developed at The Children's Hospital of Philadelphia (CHOP). CHOP has 550 beds and maintains designation by the American Nurses Credentialing Center as a Magnet Hospital. CHOP directs all novice nurses to complete an 18-month nurse residency program offered by The University HealthSystem Consor- tium. ${ }^{[21]}$ CHOP also offers formal, structured classes for experienced nurses who want to serve as preceptors.

At CHOP, nurse leaders identified the need for a preceptor intervention in the PICU: there was an unexplained increase in the staff turnover rate, and in turn increased demands placed on the unit's preceptors. Accordingly, the Preceptor Support program was implemented in the PICU.

The preceptors expressed poor morale and poor satisfaction and lack of support and direction when they were orienting the new nurse graduates. We therefore decided to augment and enhance our traditional evidence-based classroom preceptor program. ${ }^{[17,22,23]}$

\subsection{Objectives}

The aims of the Preceptor Program were to increase knowledge among novice nurses; to increase novice nurse satisfaction with their preceptors; to increase preceptor competence; and to increase preceptor satisfaction.

We thus undertook a quasi-experimental study in which a cohort of newly hired novice nurses and their assigned preceptors participated in this new Preceptor Program. The knowledge and competence of novices and the satisfaction of both novices and preceptors were assessed.

\section{Methods}

\subsection{Protection of human subjects}

This project was reviewed and sanctioned by the local IRB. Both novice nurses and preceptors participated on a voluntary basis. All data were de-identified, entered into SPSS, and kept on a secure device.

\subsection{Setting and sample}

All novice nurses starting PICU orientation between June 2014 and November 2014 were enrolled in the preceptor program, though data collection for this project was optional (with no additional compensation). All senior nurses selected to serve as preceptors were invited to use the new tools and systems developed. Participation was likewise without additional compensation.

\subsection{Data collection and analysis}

Aim 1: Increase knowledge among novice nurses at the close of PICU orientation

Gains in novice nurse knowledge were measured by changes in mean scores on a 75-item multiple-choice examination, the Basic Knowledge Assessment Tool (BKAT). ${ }^{[24]}$ This was administered at the outset of the orientation and upon its completion. All novice nurses who began orientation during June 2014-December 2014 took the examination as required by administration. 
Aim 2: To increase novice nurse satisfaction with their preceptor

A 20-item scale Likert scale instrument, the Satisfaction of Preceptor's Teaching Behavior, allowed new nurses to evaluate preceptor performance. A 4 point scale was used to indicate agreement with various statements; all of the statements were phrased such that a higher score indicated greater satisfaction. The mean scores obtained at the end of the program were compared to historical controls from the original study of Lee $\mathrm{et} \mathrm{al} .{ }^{[25]}$

\section{Aim 3: Increased self-assessment of preceptor nurse com- petence}

Preceptor nurse competence was assessed on a Nurse Competency Scale modified from Meretoja, Isoaho, \& LeinoKilpi ${ }^{[26]}$ A 1-7 scale assessed preceptor self-reported competency $(1=$ lack ability, $2=$ novice, $3=$ advanced beginner, $4=$ competent, $5=$ more than competent, $6=$ nearing mastery and $7=$ expert) for a variety of tasks. The change in preceptor self-reported competency attributable to the program was measured by comparing mean scores for preceptors prior to the intervention and again, at the end of orientation.

\section{Aim 4: Increase preceptor satisfaction}

Preceptor satisfaction was assessed using a 15-item Likert (1-4) scale, the Preceptor's Perception Scale introduced by Lee, Tzeng, Lin \& Yeh. The change in preceptor satisfaction attributable to the program was measured by comparing mean scores between participants and a convenience sample who served as preceptors prior to May 2014.

\subsection{Sample size and statistical assessment}

A power analysis/sample size calculation performed prior to implementation (based on the expected distribution of the data and what would qualify as clinically relevant differences) suggested $80 \%$ power could be attained with a sample size of approximately 20 preceptors and 20 novice nurses. All tests of significance used the appropriate independent or paired T-test, with alpha set at $p=.05$.

\subsection{Preceptor support enhancements}

Five evidence-based interventions were developed and implemented to improve the performance of nurse preceptors and ultimately effect novice nurses' educational experiences and outcomes.

Grab and Go Teaching Bags were created to help prepare novices for 6 high-stakes procedures performed in the PICU: blood transfusion, central line care, gastrostomy tube care, cardiac medication administration, fluid and electrolyte correction and checking the content of the emergency code cart. Each Grab and Go bag contained all equipment needed to

Published by Sciedu Press perform the procedure (e.g., for blood transfusion, the bag contained: specimen tubes, labels, blood tubing and transfusion forms) as well as printed copies of the policies and procedures for the specific task. Also included was a printed card with teaching tips. These teaching bags were developed after a series of focus groups identified specific gaps, either in terms of deficient skills or inadequate adherence to policies and procedures. It was understood that preceptors knew how to perform the procedures, but that the provision of these resources would make it easier for them to teach the skills, and to be sure that the teaching was complete. Usage was not formally tracked (as signing for the material is totally contrary to the idea of "grab and go") but anecdotally the preceptors reported their teaching was more comprehensive and they were less stressed teaching all the components for these procedures.

A private and secure intranet site for preceptors was created in SharePoint labeled: "PICU Orientation Support Program". This secure site was built to facilitate communication among preceptors and to track the progress of novices. Evidence and best practices were posted and an active discussion board provided guidance for preceptors. Case presentations, useful teaching videos, and other instructional resources were shared in real time. Powerpoint presentations and video presentations from critical care continuing education programs were also uploaded for use by all preceptors and evidenced based articles were uploaded. The result was a consistent location for up to date teaching with up to date forms and materials. Reporting the use of this electronic platform was not a formal aim of the project, however data were collected passively by systems usage logs.

The intranet site for preceptors was also used to host the Novice Nurse Competency Passport. The Passport was a real time log recording the novices' progress through the program. The Passport was designed and developed by a team of nurse educators, clinical nurse specialists and orientation coordinators. It listed the skills, competencies and knowledge the new nurse was expected to have mastered at the close of the 20-week orientation. The Passport then allowed assigned preceptors to privately document each novice nurse's accumulating skills and competencies. Prior to the use of the Novice Nurse Competency Passport, preceptors were encouraged, but not required to record the novice's attainment of educational milestones using a binder stored on the unit. There was no formal testing of the novice nurses and there were no formal "graduation requirements" for the novice nurse; rather, at week 20 , unless there were compelling circumstances to the contrary, all novice nurses were designated for full duty. The same way a traveler's passport can be used to collect immigration stamps, the Novice Nurse Compe- 
tency Passport was then used to record the novices' progress. The Passport obviated the need for paper documentation but more importantly was able to document deficiencies: for example, the lack of preceptor and novice nurse signature, under "blood transfusions" by week 6 triggers a preceptor to be on alert for opportunities to teach this skill and for the novice nurse to seek out opportunities for learning. Again, reporting of the use of The Competency Passport was not a formal aim of the project, but data for this too were provided passively by systems usage logs.

Bi-weekly Huddles with the Educational Nurse Specialist, Orientation Coordinators, and preceptors assured that coaching and consultation was provided to those preceptors. Case examples were presented and strategies to improve teaching were discussed.

Preceptor Checklists. In response to a concern that preceptors inconsistently applied appropriate principles, and in recognition that checklists can help avoid errors of omission, ${ }^{[27]}$ a Preceptor Checklist was developed. This Checklist covered four important tasks and was phrased in the form of questions: namely, did the preceptor and novice nurse review the "Passport" before the start of the shift? Did the preceptor and novice nurse explicitly discuss the learning plan and formulate goals from the Passport and assignment of the day? Did the preceptor obtain and refer to printed policies and procedures when teaching skills? And, last, did the preceptor say three encouraging words?

\section{Results}

A total of 68 preceptors participated in baseline (preintervention) data collection. There were 37 preceptors and 30 novice nurses who served in the PICU from June 2014 through December 2014 and participated in the program.

\section{Aim 1: Increase knowledge among novice nurses at the close of PICU orientation}

Novice nurses' mean competency scores (BKAT) improved significantly (paired $t$-tests, $p<.001$ ). At baseline, before orientation began, the mean score was $73 \%$. (SD 22; median 76; range: 56-88). After the program, the mean score improved to $83 \%$ (SD 7; median 85; range: 69-95) (see Figure 1).

\section{Aim 2: To increase novice nurse satisfaction with their preceptor}

The mean novice nurse satisfaction score at the end of the program was 3.6, compared to the mean 3.1 value reported in the literature (see Figure 2).

\section{Aim 3: Increased self-assessment of preceptor compe-} tency

The preceptors' self-reported competency assessment at baseline was 4.7 on a 7-point scale (SD 0.63), and was 4.8 (SD $1.5)$ at the end of the intervention. This slight increase was deemed to be clinically insignificant and thus statistical testing was not performed.

\section{Aim 4: Increase preceptor satisfaction}

The Preceptor Satisfaction scores improved from a baseline reported score of 3.0 to 3.2 after the intervention $(p=.04$; SD 0.5).

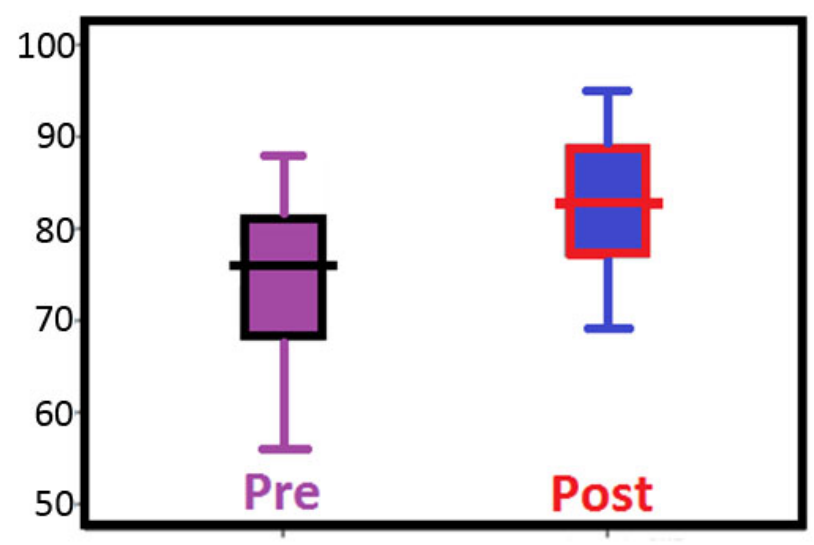

Figure 1. Box plot of BKAT results $(n=30)$, pre- and post-intervention. Novice Nurse scored significantly better after participating in the Preceptor Program $(p<.001)$

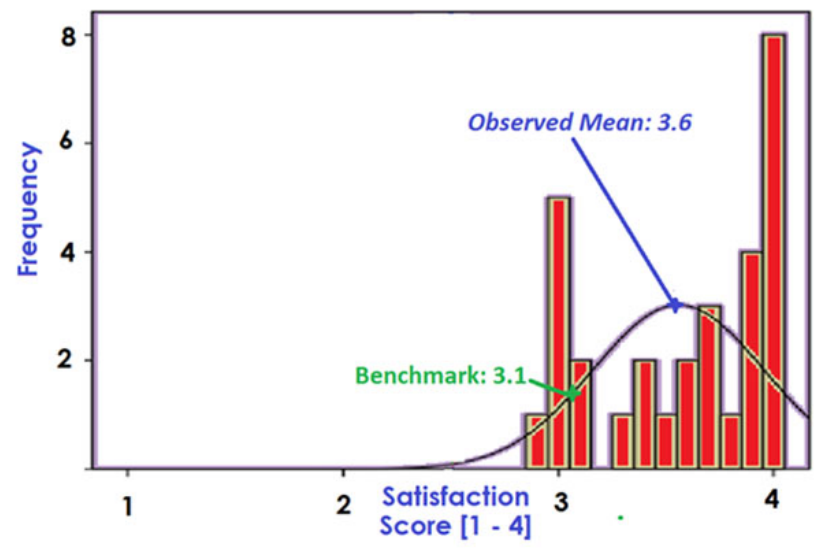

Figure 2. Novice nurse satisfaction scores: intervention group $(n=30)$ compared to historical controls

\section{Additional data: Sharepoint usage}

As noted, user engagement with the PICU Orientation Support Program was not a formal aim of the project. Nonetheless, data were collected passively by systems usage logs and were available for reporting. It was observed that the

ISSN 1925-4040 E-ISSN 1925-4059 
system averaged over 30 new users a month and over 1,400

"hits" every month. It was further observed that the Passport was used for all novice nurses and every preceptor added documentation.

\section{Discussion}

Preceptor programs are a well-established means to minimize the gap between what novice nurses know when they complete school and what their first job expects of them. Preceptor teaching can be improved with ongoing support, structure and consistent teaching methods and tools. ${ }^{[16,18,19,27]}$ We developed evidenced-based, innovative interventions that can be applied to many healthcare organizations.

In this pilot study, we present our experience attempting to improve the performance of Nurse Preceptors and the Novice nurses with a Preceptor Support Program and preceptor resources.

Our aims were to use technological and a hands on approach to increase the both the competency and satisfaction of preceptors and novice nurses. Our results indicate significant improvement in the novice nurse metrics. Preceptor satisfaction and competency were improved, albeit minimally.

We were encouraged by the improvements in novice nurse knowledge, as demonstrated by the Basic Knowledge Assessment Test (BKAT). The BKAT for the pediatric intensive care unit has had strong validity and reliability (Cronbach's alpha $=0.85$ ).

The test is easily obtained and, owing to its relative brevity (75 multiple choice questions), it may be administered before and after interventions. Toth, the creator of the BKAT, proposed $78 \%$ as the passing score and the mean score for all new nurses in our study was 83 .

The Preceptor Support Program was associated with positive assessments by the novice nurses of their preceptors' teaching and support. The novice nurse satisfaction scores here were higher than reported in the literature (3.6 compared to 3.1).

The Preceptor Support Program was also associated with strong self-assessed competency scores. Nonetheless, because baseline scores were so high (4.7 points) there was not much room for improvement and thus no improvement in this domain was demonstrated.

Last, the Preceptor Support Program was associated with increases in preceptor satisfaction as compared to baseline. Participants averaged 3.2 on the Lee scale. This compared favorably to the mean of 3.0 among preceptors before the intervention, and to the 3.0 mean seen in the original group reported by Lee et al. ${ }^{[25]}$

\section{LimitaTiONS}

The evaluation reported here of the Preceptor Support Program was a quasi-experimental study without a control group. As such, we cannot be sure that the changes seen were necessarily due to the Program itself. It is possible that there is Hawthorne (observer) effect at work, in that all participants gave an extra measure of effort, knowing that they were being observed.

A more elaborate study could randomize one large cohort of nurses to participate and another to receive ordinary orientation. Only with a control can one be confident that the effects seen were caused by the intervention. It is also possible that satisfaction measures or BKAT scores would go up over the course of orientation, independent of the intervention.

It is also possible that the study underestimates the positive effects of the program. For instance, using a checklist to ask "Did the Preceptor say three encouraging words?" may have beneficial effects that are real yet hard to measure.

Last, we acknowledge the small sample size employed. Although this sample was adequate to attain statistical significance for some metrics, as shown, it is possible that the magnitude of the effect is overstated. ${ }^{[28]}$

\section{Conclusion}

Preceptor teaching, when done well, is good for novice nurses, good for preceptors and good for the profession of nursing at large. Encouraging excellence in preceptor teaching can therefore be justified even if there were no practice-preparation gap.

The program reported here shows promise to be a costeffective means of encouraging excellence, improving teaching and utilizing methods both innovative and traditional.

Some of the methods employed here are as old as nursing itself-for instance, the Checklist's insistence that preceptors say at three encouraging words in each encounter. Other aspects are distinctly modern, such as the use of the SharePoint system. We assert that this melding is essential. New technology such as the Passport may allow a shift to competencybased promotion and thereby save money and reduce errors. Yet nursing must stay close to its roots as a humanistic profession as well. Encouraging nurses to support each other, as our program explicitly aims to do, is an essential part of any solution to the preparation-practice gap.

\section{CONFLicts OF InTEREST Disclosure}

The authors declare that there is no conflict of interest. 


\section{REFERENCES}

[1] Berkow S, Virkstis K, Stewart J, et al. Assessing new graduate nurse performance. J Nurs Adm. Nov 2008; 38(11): 468474. PMid:18997551 http://dx.doi.org/10.1097/01. NNA. 00 00339477.50219 .06

[2] Takase M, Nakayoshi Y, Teraoka S. Graduate nurses' perceptions of mismatches between themselves and their jobs and association with intent to leave employment: a longitudinal survey. Int J Nurs Stud. Dec 2012; 49(12): 1521-1530. PMid:22925850 http: //dx.doi.org/10.1016/j.ijnurstu.2012.08.003

[3] Ulrich B, Krozek C, Early S, et al. Improving retention, confidence, and competence of new graduate nurses: results from a 10-year longitudinal database. Nurs Econ. Nov-Dec 2010; 28(6): 363-376. PMid:21291057

[4] Burns P, Poster EC. Competency development in new registered nurse graduates: closing the gap between education and practice J Contin Educ Nurs. Feb 2008; 39(2): 67-73. PMid:18323143 http://dx.doi.org/10.3928/00220124-20080201-03

[5] Hickey MT. Preceptor perceptions of new graduate nurse readiness for practice. J Nurses Staff Dev. Jan-Feb 2009; 25(1): 35 41. PMid:19182556 http://dx.doi.org/10.1097/NND.0b013 e318194b5bb

[6] Kantar LD. Clinical practice of new nurse graduates in Lebanon: challenges and perspectives through the eyes of preceptors. J Contin Educ Nurs. Nov 2012; 43(11): 518-528. PMid:22880636 http: //dx.doi.org/10.3928/00220124-20120801-62

[7] Wolff AC, Pesut B, Regan S. New graduate nurse practice readiness: perspectives on the context shaping our understanding and expectations. Nurse Educ Today. Feb 2010; 30(2): 187-191. PMid:19699561 http://dx.doi.org/10.1016/j.nedt.2009.07.011

[8] Thomas CM, Bertram E, Allen RL. The transition from student to new registered nurse in professional practice. J Nurses Staff Dev. Sep-Oct 2012; 28(5): 243-249. PMid:22992640 http://dx.doi.o $\mathrm{rg} / 10.1097 / \mathrm{NND}$. Ob013e31826a009c

[9] Beecroft PC, Dorey F, Wenten M. Turnover intention in new graduate nurses: a multivariate analysis. J Adv Nurs. Apr 2008; 62(1): 4152. PMid:18352963 http://dx.doi.org/10.1111/j.1365-2 $648.2007 .04570 . x$

[10] The future of nursing: the Institute of Medicine (IOM) issues report The future of nursing: leading change, advancing health. Prairie Rose Nov-2011 Jan 2010; 79(4): 6.

[11] Theisen JL, Sandau KE. Competency of new graduate nurses: a review of their weaknesses and strategies for success. J Contin Educ Nurs. Sep 2013; 44(9): 406-414. PMid:23799789 http: //dx.doi.org/10.3928/00220124-20130617-38

[12] Jones CB. Revisiting nurse turnover costs: adjusting for inflation. J Nurs Adm. Jan 2008; 38(1): 11-18. PMid:18157000 http: //dx.doi.org/10.1097/01. NNA.0000295636.03216.6f

[13] Smith J, Crawford L. Medication errors and difficulty in first patient assignments of newly licensed nurses. JONAS Healthc Law Ethics Regul. Sep 2003; 5(3): 65-67. PMid:12972949 http: //dx . doi .o rg/10.1097/00128488-200309000-00006
[14] Pine R, Tart K. Return on investment: benefits and challenges of baccalaureate nurse residency program. Nurs Econ. Jan-Feb 2007; 25(1): 13-18, 39, 13; quiz 19.

[15] Trepanier S, Early S, Ulrich B, et al. New graduate nurse residency program: a cost-benefit analysis based on turnover and contract labor usage. Nurs Econ. Jul-Aug 2012; 30(4): 207-214. PMid:22970551

[16] Phillips C, Kenny A, Esterman A, et al. A secondary data analysis examining the needs of graduate nurses in their transition to a new role. Nurse Educ Pract. Mar 2014; 14(2): 106-111. PMid:23932667 http://dx.doi.org/10.1016/j.nepr.2013.07.007

[17] Alspach G. Recognizing and rewarding nurse preceptors in critical care. Some answers. Crit Care Nurse. Apr 2003; 23(2): 13-20. PMid:12725191

[18] Henderson A, Eaton E. Assisting nurses to facilitate student and new graduate learning in practice settings: what 'support' do nurses at the bedside need? Nurse Educ Pract. May 2013; 13(3): 197-201. http://dx.doi.org/10.1016/j.nepr.2012.09.005

[19] Steffan KP, Goodin HJ. Preceptors' perceptions of a new evaluation tool used during nursing orientation. J Nurses Staff Dev. May-Jun 2010; 26(3): 116-122. PMid:20508426 http://dx.doi.org/10. 1097/NND . Ob013e31819aa116

[20] Creakbaum EL. Creating and implementing a nursing role for RN retention. J Nurses Staff Dev. Jan-Feb 2011; 27(1): $25-$ 28. PMid:21263277 http://dx.doi.org/10.1097/NND.0b013 e318199459f

[21] Fink R, Krugman M, Casey K, et al. The graduate nurse experience: qualitative residency program outcomes. J Nurs Adm. Jul-Aug 2008; 38(7-8): 341-348. PMid:18690125 http://dx.doi.org/10.1097 /01. NNA. 0000323943.82016 .48

[22] Alspach G. Recognizing and rewarding preceptors: do you bother? A survey. Crit Care Nurse. Apr 2002; 22(2): 16-17. PMid:11961939

[23] Alspach J. A preceptor training program for professional healthcare staff. Aliso Viejo, CA: American Association of Critical Care Nurses. 2000.

[24] Runton NG, Toth JC. Introducing the Basic Knowledge Assessment Tool for pediatric critical care nursing (PEDS-BKAT). Crit Care Nurse. Jun 1998; 18(3): 67-72. PMid:9677940

[25] Lee TY, Tzeng WC, Lin CH, et al. Effects of a preceptorship programme on turnover rate, cost, quality and professional development. J Clin Nurs. Apr 2009; 18(8): 1217-1225. PMid:19320789 http://dx.doi.org/10.1111/j.1365-2702.2008.02662.x

[26] Meretoja R, Isoaho H, Leino-Kilpi H. Nurse competence scale: development and psychometric testing. J Adv Nurs. Jul 2004; 47(2): 124-133. PMid:15196186 http://dx.doi.org/10.1111/j.136 5-2648.2004.03071.x

[27] Pronovost PJ, Berenholtz SM, Goeschel C, et al. Improving patient safety in intensive care units in Michigan. J Crit Care. Jun 2008; 23(2): 207-221. PMid:18538214 http://dx.doi.org/10.1016 /j.jcrc.2007.09.002

[28] Button KS, Ioannidis JPA, Mokrysz C, et al. Power failure: why small sample size undermines the reliability of neuroscience. Nat Rev Neurosci. 2013; 14(5): 365-376. PMid:23571845 http://dx .doi.org/10.1038/nrn3475 